\title{
BMJ Open Incidence and predictors of mortality among children admitted to the pediatric intensive care unit at the University of Gondar comprehensive specialised hospital, northwest Ethiopia: a prospective observational cohort study
}

\author{
Nahom Worku Teshager, ${ }^{1}$ Ashenafi Tazebew Amare, ${ }^{1}$ Koku Sisay Tamirat (D) ${ }^{2}$
}

To cite: Teshager NW, Amare AT, Tamirat KS. Incidence and predictors of mortality among children admitted to the pediatric intensive care unit at the University of Gondar comprehensive specialised hospital, northwest Ethiopia: a prospective observational cohort study. BMJ Open 2020;10:e036746. doi:10.1136/ bmjopen-2019-036746

- Prepublication history for this paper is available online. To view these files, please visit the journal online (http://dx.doi org/10.1136/bmjopen-2019036746).

Received 03 January 2020 Revised 10 August 2020 Accepted 21 September 2020

Check for updates

(C) Author(s) (or their employer(s)) 2020. Re-use permitted under CC BY-NC. No commercial re-use. See rights and permissions. Published by BMJ.

${ }^{1}$ Department of Pediatrics and Child Health, School of Medicine, College of Medicine and Health Science, University of Gondar, Gondar, Ethiopia

${ }^{2}$ Epidemiology and Biostatistics, Institute of Public Health,

College of Medicine and Health Sciences, University of Gondar, Gondar, Ethiopia

Correspondence to

Koku Sisay Tamirat;

kokusisay23@gmail.com

\section{ABSTRACT}

Objective To determine the incidence and predictors of mortality among children admitted to the paediatric intensive care unit (PICU) at the University of Gondar comprehensive specialised hospital, northwest Ethiopia. Design A single-centre prospective observational cohort study.

Participants A total of 313 children admitted to the ICU of the University of Gondar comprehensive specialised hospital during a one-and-a-half-year period.

Measurements Data were collected using standard case record form, physical examination and patient document review. Clinical characteristics such as systolic blood pressure, pupillary light reflex, oxygen saturation and need for mechanical ventilation (MV) were assessed and documented within the first hour of admission and entered into an electronic application to calculate the modified Pediatric Index of Mortality 2 (PIM 2) Score. We fitted the Cox proportional hazards model to identify predictors of mortality.

Result The median age at admission was 48 months with IQR: 12-122, 28.1\% were infants and adolescents accounted for $21.4 \%$. Of the total patients studied, $59.7 \%$ were males. The median observation time was 3 days with (IQR: 1-6). One hundred and two (32.6\%) children died during the follow-up time, and the incidence of mortality was 6.9 deaths per 100 person-day observation. Weekend admission (adjusted HR (AHR)=1.63, 95\% Cl: 1.02 to 2.62), critical illness diagnoses (AHR=1.79, 95\% $\mathrm{Cl}: 1.13$ to 2.85), need for MV (AHR=2.36, 95\% Cl: 1.39 to 4.01$)$ and modified PIM 2 Score (AHR=1.53, 95\% Cl: 1.36 to 1.72) were the predictors of mortality.

Conclusion The rate of mortality in the PICU was high, admission over weekends, need for MV, critical illness diagnoses and higher PIM 2 scores were significant and independent predictors of mortality.

\section{INTRODUCTION}

Though paediatric intensive care units (PICUs) are essential areas of service to save the lives of children with acute neurological
Strength and limitation of this study

- This study was a prospective cohort study and had used better statistical functions (survival analysis) for better estimation and prediction of mortality.

- This study could help clinicians and healthcare planners practice evidence-based medicine in a resource-limited setting such as ours.

- The Pediatric Index of Mortality 2 scoring was done based on 9 out of 11 parameters as there was no arterial blood gas analyser in our set-up during the study period that might result in misclassification.

deterioration, respiratory distress, cardiovascular compromise, severe infections, accidental poisoning and other life-threatening conditions; organisational details of paediatric ICUs in low-income settings are lacking. ${ }^{12}$

Published data on paediatric critical care in low-income countries remain sparse, making practice modification and outcome improvement difficult. Also, most studies done on predictors of mortality in the PICUs are from high-income countries and are dependent on clinical and laboratory indices, which are not readily available in low-income countries. ${ }^{3}$ The few studies that considered epidemiologic and sociodemographic factors were retrospective and cross-sectional, and most did not consider essential parameters. ${ }^{4}$ Determining the risk factors of mortality among children admitted to the paediatric intensive care will be crucial to prioritise and tunnel resources to the most fruitful practice based on the prediction of patient outcomes, especially in resource-limited setups such as ours.

This study aimed to determine the incidence and predictors of mortality among 
children admitted to a PICU at the University of Gondar comprehensive specialised hospital. It will add to the knowledge of mortality and its predictors, thereby hoping to plan the most efficient method of intervention for those at higher mortality risk, thus contributing to recovery as well as making the assessment of the performance of the services delivered.

\section{METHODS}

\section{Study design, period and setting}

A single-centre prospective cohort study was conducted among children aged 1 month to 18 years admitted to the PICU at the University of Gondar comprehensive specialised hospital from 1 February 2018 to 30 July 2019.

The PICU has six beds with electronic monitors and one mechanical ventilator; on average, there are about 25 paediatric critical care admissions per month. The organisational detail of the PICU in this hospital is lacking. Team composition is often limited to a general paediatrician, resident, interns and a handful of senior-level nurses, but there are no paediatric intensivists, respiratory therapists, pharmacists and dieticians.

\section{Population and sample}

Patients who stayed for more than 2 hours in the hospital were included in the study. We excluded patients having incomplete data, and surgical patients admitted only for recovery purposes from the study.

The sample size for this study was determined using a single population proportion of $\mathrm{p}=21 \%$, from previous Bangladesh study ${ }^{2}$ with a $5 \%$ margin of error; the sample size became 254 , and after adding $10 \%$ contingency, the sample became 279. A total of 376 patients were admitted to the PICU during the study period. We collected data from 327 patients who fulfilled the inclusion criteria. Fourteen patients were excluded from the study due to incomplete data.

\section{Data collection procedure}

Data were collected by treating physicians using standard case record form after receiving consent from caretakers. Clinical characteristics such as systolic blood pressure, pupillary light reflex, oxygen saturation and need for mechanical ventilation (MV) were assessed and documented within the first hour and entered into an electronic application to calculate the modified Pediatric Index of Mortality 2 (PIM 2) Score. We took sociodemographic data and medical history by interview; and diagnosis, laboratory indices and the clinical course during the hospital by chart review at discharge. We used WHO International Classification of Diseases 10th version (ICD-10) for disease category, and only the primary diagnoses were used for ICD-10 assignment in patients having multiple diagnoses. The collected data were double checked by the data collector and the principal investigator. There were orientations and training about data collection and the study's objective every 3 months and demonstration every Monday for treating physicians and data collectors. The principal investigator supervised the overall process and checked the completeness of case record forms everyday. No direct patient care was provided by investigators, who only accessed patients' records.

\section{Variable of the study and operational definitions}

The primary dependent variable was time to death (event). In contrast, sociodemographic characteristics included age, sex, relation with the caregiver, caregiver's educational status and occupation. Clinical characteristics included duration of illness before admission, source of admission, critical illness diagnosis, comorbidity, nutritional status, vaccination status, interventions given in the PICU and before admissions such as fluid resuscitation, modified PIM 2 Score, multiorgan dysfunction syndrome (MODS) and complications.

Event (death): is defined as a patient who died in the hospital during treatment.

Censored: refers to patients who were discharged alive from the PICU or those with no event of interest.

Length of stay (LOS): refers to the duration of stay in days from the date of admission to the date of discharge.

Short-term outcome: the outcome of the patient until he or she leaves the hospital.

Critical illness: refers to sepsis, severe sepsis or septic shock within 24 hours of admission or acute respiratory distress syndrome during PICU admission.

MODS: refers to a potentially reversible physiologic derangement in two or more organ systems

\section{Data processing and analysis}

After we checked the data for its consistency and completeness, we entered data into EpiData V.3.1 and exported to STATA V.14 for cleaning and analysis. Descriptive statistics such as mean, median and proportions were carried out to summarise baseline characteristics and admission patterns. Also, summary statistics such as life table, log-rank test and Kaplan-Meier curves were computed to determine the incidence rate of death and to compare survival curves between the different categories of the explanatory variables.

Both bivariate and multivariate Cox proportional hazards models were used to identify the predictors. Variables with $\mathrm{p}$ value $<0.2$ in the bivariate analysis were entered into the multivariate proportional hazard model. Ninety-five per centCI of HRs were computed, and variables with $\mathrm{p}$ value $<0.05$ in the multivariate Cox proportional hazards model were considered significantly and independently associated with the dependent variable. Cox proportional hazards model fitness was checked using the Schoenfeld residuals test.

\section{Patient and public involvement}

There was no direct patient contact, and investigators accessed only patient records.

\section{RESULT}

\section{Sociodemographic characteristics}

A total of 313 patients out of 376 admitted during the 18-month study period were included in the final analysis. 
Table 1 Sociodemographic characteristics of patients

Percentages

Characteristics

Frequency (\%)

\begin{tabular}{|c|c|c|}
\hline \multicolumn{3}{|l|}{ Age in months } \\
\hline$\leq 12$ & 88 & 28.1 \\
\hline $13-24$ & 29 & 9.3 \\
\hline $25-60$ & 66 & 21.1 \\
\hline $61-132$ & 63 & 20.1 \\
\hline$>132$ & 67 & 21.4 \\
\hline \multicolumn{3}{|l|}{ Sex } \\
\hline Male & 188 & 59.7 \\
\hline \multicolumn{3}{|l|}{ Vaccination status } \\
\hline Complete & 203 & 64.9 \\
\hline Incomplete/unvaccinated & 110 & 35.1 \\
\hline \multicolumn{3}{|l|}{ Comorbid illness $(n=43)$} \\
\hline $\begin{array}{l}\text { Congenital malformations/ } \\
\text { genetic disorders }\end{array}$ & 12 & 27.9 \\
\hline $\begin{array}{l}\text { Cerebral palsy with or } \\
\text { without seizure disorders }\end{array}$ & 11 & 25.6 \\
\hline Chronic kidney disease & 7 & 16.3 \\
\hline HIV/AIDS & 6 & 14 \\
\hline Others & 7 & 16.3 \\
\hline
\end{tabular}

The median age at admission was 48 months with IQR: $12-122$, with a male-to-female ratio of $1.7: 1$, as shown in table 1 . The majority of caregivers $(92.9 \%)$ were parents. More than three-fourth $(77.6 \%)$ of caregivers had no formal education, and $71.2 \%$ were farmers. Most patients were admitted in the spring season (38.3\%), followed by winter $(27.2 \%)$ (table 1 ).

\section{The clinical condition of admitted children}

The primary source of admissions in the PICU was the emergency room $(60.4 \%)$, inpatient paediatrics wards $(13.1 \%)$ and referrals from other facilities $(11.8 \%)$. More than three-fourth $(77 \%)$ of patients were admitted over weekdays and $41.5 \%$ in the night shift. The median duration of illness before any health facility visit and admission to PICU was 3 (IQR: 1-7) and 6 (IQR: 3-13) days. Onethird of patients had critical illness diagnoses, of which $41 \%$ had sepsis, $47 \%$ septic shock, and the remaining $(12 \%)$ had acute respiratory distress syndrome. About one-third of patients $(30.7 \%)$ had MODS. The minimum modified PIM 2 Score was -6.46 (with predicted mortality rate $=0.2 \%$ ), and the maximum score was 2.47 (predicted mortality rate $=92.2 \%$ ). The mean predicted mortality rate based on the modified PIM 2 Score was 11.14\%, which gave the standard mortality ratio of 2.94 (table 2 ).

\section{ICU outcomes and the incidence of mortality}

Nearly one-third of patients $(32.6 \%)$ died in the PICU. Severe sepsis or multiorgan failure $(41.2 \%)$ was the leading immediate cause of death in the PICU followed by respiratory failure $(23.5 \%)$, brain herniation $(21.6 \%)$
Table 2 Clinical condition of patients

\begin{tabular}{lcl} 
Characteristics & Frequency & $\begin{array}{l}\text { Percentages } \\
\text { (\%) }\end{array}$ \\
\hline $\begin{array}{l}\text { Duration of illness before PICU } \\
\text { admission in days }\end{array}$ & \\
$\quad \leq 6$ days & 71 & 22.7 \\
$>6$ days & 242 & 77.7
\end{tabular}

Multiorgan dysfunction

syndrome

\begin{tabular}{|rrr|}
\hline Yes & 96 & 30.6 \\
\hline No & 217 & 69.4 \\
\hline Sources of admission & & \\
\hline Home & 36 & 11.5 \\
Other facilities & 37 & 11.8 \\
\hline Emergency room & 189 & 60.4 \\
Wards and operating rooms & 51 & 16.3 \\
\hline
\end{tabular}

Need for mechanical

ventilation

\begin{tabular}{|rrr}
\hline Yes & 37 & 11.8 \\
\hline No & 276 & 88.2 \\
\hline Nutritional status, z-score & & \\
\hline Normal & 163 & 52.1 \\
\hline Moderate acute malnutrition & 50 & 16 \\
\hline Severe acute malnutrition & 100 & 31.9 \\
\hline Reasons for PICU admission & & \\
\hline Altered mental status & 145 & 46.3 \\
\hline Respiratory failure & 82 & 26.5 \\
\hline Sepsis & 59 & 18.8 \\
\hline Shock & 55 & 17.6 \\
\hline Seizure & 46 & 14.7 \\
\hline Diabetic ketoacidosis & 24 & 7 \\
\hline Acute kidney injury & 24 & 7 \\
\hline Congestive heart failure & 21 & 6.7 \\
\hline Haemorrhage & 14 & 4.5 \\
\hline Trauma & 6 & 1.9 \\
\hline Others & 23 & 7.3 \\
\hline
\end{tabular}

PICU, paediatric intensive care unit.

and cardiac arrest (12.7\%). Fifty-six patients (17.9\%) developed complications during their stay in the PICU, including hospital-acquired sepsis (46.4\%), hospitalacquired pneumonia $(17.9 \%)$ and mechanical ventilatorassociated complications $(10.7 \%)$.

Study subjects were followed during the study period, which gave a total of 1473 person-day observations (49.1 person-months), and the median LOS in the ICU was 3 (IQR: 1-6) days. Of the 313 participants, 102 (32.6\%) died during the follow-up time. The incidence of mortality was 6.9 deaths per 100 person-day observations (95\% CI: 5.34 to 8.34 deaths per 100 person-day). Among deaths 


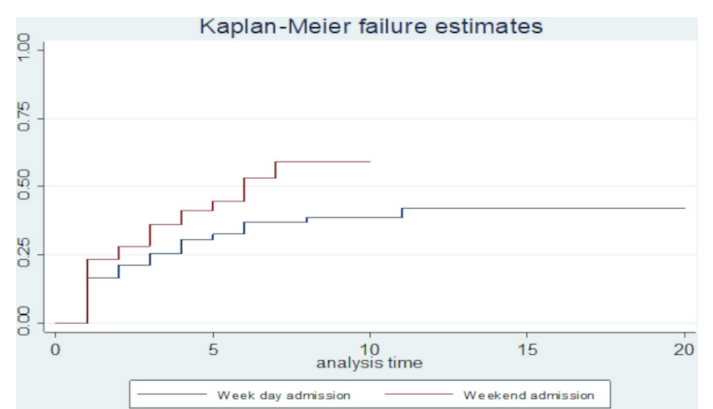

Figure 1 Kaplan-Meier failure (death) estimates curves by days of admission.

reported, more than half $(53.9 \%)$ died within 24 hours, 13 (12.7\%) died between 24 and 48 hours and the remaining died after 48 hours of admission. Differences in all variables at baseline between strata were determined using the log-rank $\left(\chi^{2}\right)$ test, and the equality of hazard was assessed for the different explanatory variables. KaplanMeier failure curve was plotted for weekend admission ( $p$ value $=0.039)$, and critical illness $(\mathrm{p}$ value $=0.0001)$ shows a significant differenceand.(figures 1 and 2)

\section{Predictors of mortality in the PICU}

The Cox proportional hazards model was fitted to identify predictors of mortality. From the multivariate analysis, caregivers' occupation, weekend admission, critical illness diagnoses, PIM 2 Score and need for MV were predictors of mortality. Mortality was 65\% lower for those whose caregivers were government employees than farmers $(\mathrm{AHR}=0.35,95 \% \mathrm{CI}$ : 0.14 to 0.89$)$. The hazard of mortality was 1.63 times higher for patients admitted over weekends $(\mathrm{AHR}=1.63,95 \% \mathrm{CI}: 1.02$ to 2.60$)$ and 1.79 times higher in patients who had critical illness diagnoses $(\mathrm{AHR}=1.79,95 \% \mathrm{CI}: 1.13$ to 2.85$)$ compared with weekday admission and those without critical illness diagnosis, respectively. Similarly, each one-unit increase in the modified PIM 2 Score increased the hazard of mortality 1.53 times, keeping other variables constant $(\mathrm{AHR}=1.53$, $95 \%$ CI: 1.36 to 1.72 ). Also, those patients who met the criteria for MV, the hazard of mortality was 2.36 times higher compared with those who did not need MV $(\mathrm{AHR}=2.36,95 \%$ CI: 1.39 to 4.01$)$ (table 3$)$.

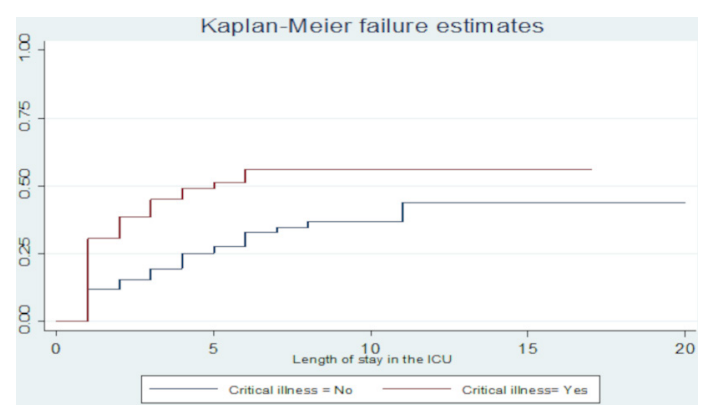

Figure 2 Kaplan-Meier failure (death) estimates curves by critical illness. ICU; intensive care unit.

\section{DISCUSSION}

Our study is the first report from a prospective study in a PICU in Ethiopia that demonstrates the mortality is high and identified predictors of mortality such as lack of appropriate human resources (weekend admission), critical illness diagnosis and need for MV. These findings help clinicians, and healthcare planners practice evidence-based medicine in a resource-limited setting and effective prognosis tailored care and resource utilisation.

The proportion of mortality $(32.6 \%)$ in this study with a rate of 6.92 deaths per 100 person-day observation was consistent with the mortality rate in retrospective cross-sectional studies done in the same PICU from 2013 to $2016(30.9 \%),{ }^{5}$ and other studies in low-income countries in Africa which ranged from 25\% in Mozambique to $50 \%$ in Rwanda. ${ }^{6-8}$ However, it is lower than the finding of a retrospective cross-sectional study done in Jimma, Ethiopia, $(40 \%) .{ }^{9}$ The difference could be attributed to the higher proportion of trauma patients admitted in their PICU compared with ours. When we compare it with other lower and middle-income countries, the mortality rate in our PICU is higher than the mortality rates in studies done in Pakistan $(14 \%){ }^{10}$ and India $(10.58 \%) .{ }^{11}$ The possible explanation for the observed discrepancies might be suboptimal care, the inadequacy of diagnostic and interventional facilities in our PICU.

Children admitted over the weekends had nearly two times increased risk of mortality than those admitted over weekdays, consistent with the findings of studies done in Canada, Finland and Austria. ${ }^{12-14}$ This increased mortality over weekends might be due to failure to promptly recognise deteriorations among patients in the wards and other sources as a result of reduced staffing ratios. Access to diagnostic services is limited during weekends, which limits the likelihood of arriving at diagnoses. Furthermore, there could be unrecognised deteriorations during handoff and round times and delays in administering interventions. However, our finding was not supported by three American studies and studies done in the UK and the Ireland. ${ }^{1516}$ This discrepancy could be explained by the better standard of care they have and 24 hours around the clock staffing. Better weekend coverage and full hour staffing are recommended for a better critical care delivery.

This study also highlighted how being a caregiver who is a government employee was associated with lower risk mortality compared with caregivers of peasants. This finding could be explained by differences in healthseeking behaviour, access to funds for transportation and early identification of danger signs between them.

The child who had a critical illness diagnosis had an increased risk of mortality than those who had not. This difference could be because patients with critical illnesses have a low reserve of physiologic function. This finding was consistent with other studies. ${ }^{1718}$ 
Table 3 Bivariate and multivariate Cox proportional hazard model fit for different independent variables

\begin{tabular}{|c|c|c|c|c|}
\hline \multirow[b]{2}{*}{ Variables } & \multicolumn{2}{|l|}{ Status } & \multirow[b]{2}{*}{ CHR (95\% Cl) } & \multirow[b]{2}{*}{ AHR (95\% Cl) } \\
\hline & Event & Censored & & \\
\hline \multicolumn{5}{|l|}{ Age (months) } \\
\hline $13-24$ & 10 & 19 & $0.98(0.47$ to 2.12$)$ & $1.40(0.65$ to 3.04$)$ \\
\hline $25-60$ & 26 & 40 & 1.30 (0.75 to 2.23$)$ & $1.15(0.63$ to 2.08$)$ \\
\hline$>132$ & 18 & 49 & $0.92(0.50$ to 1.67$)$ & $1.61(0.84$ to 3.08$)$ \\
\hline \multicolumn{5}{|l|}{ Address } \\
\hline Urban & 28 & 43 & 1 & 1 \\
\hline Rural & 74 & 168 & 0.73 (0.47 to 1.13$)$ & 0.63 (0.37 to 1.05$)$ \\
\hline \multicolumn{5}{|c|}{ Caregivers' level of education } \\
\hline Farmers & 72 & 151 & 1 & 1 \\
\hline Merchants and private & 9 & 23 & 0.82 (0.41 to 1.64$)$ & $1.06(0.47$ to 2.35$)$ \\
\hline Government employee & 7 & 24 & 0.50 (0.22 to 1.16$)$ & $0.35(0.14 \text { to } 0.89)^{*}$ \\
\hline Unemployed & 14 & 13 & 1.61 (0.91 to 2.86$)$ & $1.11(0.55$ to 2.24$)$ \\
\hline \multicolumn{5}{|l|}{ Day of admission } \\
\hline Weekday & 71 & 170 & 1 & 1 \\
\hline Weekend & 31 & 41 & 1.47 (0.96 to 2.26$)$ & $1.63(1.02 \text { to } 2.60)^{*}$ \\
\hline \multicolumn{5}{|l|}{ Source of admission } \\
\hline
\end{tabular}

Duration of illness before PICU

admission

\begin{tabular}{|c|c|c|c|c|}
\hline$<6$ days & 39 & 107 & 1 & 1 \\
\hline$\geq 6$ days & 63 & 104 & 1.43 (0.96 to 2.12$)$ & 0.97 (0.62 to 1.54$)$ \\
\hline \multicolumn{5}{|l|}{ Comorbidities } \\
\hline Yes & 17 & 26 & $1.31(0.78$ to 2.21$)$ & 0.66 (0.36 to 1.23$)$ \\
\hline \multicolumn{5}{|l|}{ Critical illness diagnosis } \\
\hline Yes & 49 & 51 & 2.05 (1.39 to 3.04$)$ & $1.79(1.13 \text { to } 2.85)^{\star}$ \\
\hline \multicolumn{5}{|l|}{ Nutritional status, z-score } \\
\hline Normal & 45 & 118 & 1 & 1 \\
\hline Moderate acute malnutrition & 15 & 35 & 1.19 (0.66 to 2.14$)$ & 1.49 (0.79 to 2.82$)$ \\
\hline Severe acute malnutrition & 42 & 58 & 1.67 (1.09 to 2.55$)$ & 1.69 (0.94 to 2.61$)$ \\
\hline \multicolumn{5}{|l|}{ Mechanical ventilation need } \\
\hline No & 79 & 197 & 1 & 1 \\
\hline Yes & 23 & 14 & 1.93 (1.20 to 3.10$)$ & $2.36(1.39 \text { to } 4.01)^{\star}$ \\
\hline Complications in the PICU & & & & \\
\hline
\end{tabular}


Table 3 Continued

\begin{tabular}{lcccc}
\hline & Status & & & \\
\cline { 2 - 3 } Variables & Event & Censored & CHR (95\% Cl) & AHR (95\% Cl) \\
\hline No & 86 & 190 & 1 & 1 \\
Yes & 16 & 21 & $2.39(1.20$ to 4.73) & $1.62(0.79$ to 3.31$)$ \\
Fluid resuscitation intervention before PICU admission & & & \\
No & 44 & 105 & 1 & 1 \\
Yes & 58 & 106 & $1.24(0.83$ to 1.84$)$ & $0.92(0.59$ to 1.44$)$ \\
\hline
\end{tabular}

*Shows statistical significance at a $p$ value of 0.05 .

AHR, adjusted HR; CHR, crude HR; PICU, paediatric intensive care unit.

Among many disease severity assessment tools at baseline, PIM 2 does not need extensive laboratory investigation, and it is not affected by subsequent interventions since it is scored within 1 hour of admission resulting in early identification of the severity of illness and stratification of children for necessary intervention, ${ }^{19}$ which in turn helps in counselling caregivers of sick children. We used a modified PIM2 Score as there was no arterial blood gas analyser in our PICU during the study period. A unit increment in the modified PIM 2 Score doubled the hazard of mortality, which shows the score is sensitive in detecting morality, and this scoring system is also validated and applicable in many PICUs across the world. ${ }^{20-24}$ The higher observed mortality rate than the predicted ones by the modified PIM 2 Score in our study indicates the poor quality of intensive care in our setting. Using the modified PIM 2 Score to focus the care on those with dangerous modified PIM2 scores, prognosticate outcomes and tunnel resources to the most in need patients will improve the critical care outcome in low-income settings.

Patients who had respiratory failure, and those who met the criteria for MV, had increased mortality than those who did not have indications for ventilation. This finding is consistent with the findings from other studies. ${ }^{25}{ }^{26}$ Patients who need MV tend to have advanced disease stages. This finding can also be attributed to a limited number of mechanical ventilators in our PICU. There might also be unrecognised ventilator-associated complications in those who were placed on a mechanical ventilator.

\section{Strength and limitations of the study}

This study is a prospective cohort study with a better statistical function (survival analysis). The PIM 2 scoring was based on 9 out of 11 parameters as there was no arterial blood gas analyser in our PICU during the study period. The availability of medical equipment and PICU quality of care and their impact on patient survival was not adequately assessed using standard parameters. Paediatric critical care is not just about saving lives, so the degree of physiologic function retained at discharge should have been assessed using a standard checklist for all discharged patients.

\section{CONCLUSION}

The rate of mortality in the PICU was high, and admission during weekends, need for MV, critical illness diagnoses and higher modified PIM 2 Score were significant and independent predictors of mortality. Full staffing around the clock including better weekend coverages, and paying due attention for early signs of critical illness may improve intensive care outcomes. Using the modified PIM 2 Score to focus the care on those with risky scores, tunnel resources to the most in need patients and counselling of caregivers might be advisable.

Acknowledgements We are thankful to study participants, data collectors, supervisors and hospital administrators of the University of Gondar comprehensive specialised hospital. We also would like to acknowledge the department of pediatrics and child health.

Contributors All authors participated in designing the study, performed data analysis, visualisation, validation of the whole work and prepared the manuscript. NWT took part in funding acquisition, data collection, supervision and software, and other resources. All authors read and approved the final manuscript.

Funding The study was funded by the University of Gondar, Ethiopia. The funder has no role in study design, data collection, and analysis, interpretation of data, the decision to publish, or preparation of the manuscript.

Competing interests None declared.

Patient and public involvement Patients and/or the public were not involved in the design, or conduct, or reporting, or dissemination plans of this research.

Patient consent for publication Not required.

Ethics approval Ethical clearance was obtained from the Institutional Ethical Review Board of the University of Gondar's College of Medicine and Health Sciences. Informed verbal consent was obtained from the caretakers. The name or any other identifying information was not recorded on the data collection form, and all information taken from the chart was kept strictly confidential and in a safe place. The information retrieved was used only for the study purpose.

Provenance and peer review Not commissioned; externally peer reviewed.

Data availability statement Data may be obtained from a third party and are not publicly available. Data are available from the corresponding author upon reasonable request.

Open access This is an open access article distributed in accordance with the Creative Commons Attribution Non Commercial (CC BY-NC 4.0) license, which permits others to distribute, remix, adapt, build upon this work noncommercially, and license their derivative works on different terms, provided the original work is properly cited, appropriate credit is given, any changes made indicated, and the use is non-commercial. See: http://creativecommons.org/ licenses/by-nc/4.0/.

ORCID iD

Koku Sisay Tamirat http://orcid.org/0000-0001-6495-1882 


\section{REFERENCES}

1 Turner EL, Nielsen KR, Jamal SM, et al. A review of pediatric critical care in resource-limited settings: a look at past, present, and future directions. Front Pediatr 2016;4:5.

2 Hoque MS, Masud M, Ahmed A. Admission pattern and outcome in a paediatric intensive care unit of a tertiary care paediatric hospital in Bangladesh-A two-year analysis. DS (Child) HJ 2012;28:14-19.

$3 \mathrm{Wu}$ Y. Risk factors for death in pediatric intensive care unit of a tertiary children's hospital in Guangzhou city [HKU Theses], 2014.

4 Abhulimhen-lyoha BI, Pooboni SK, Vuppali NKK. Morbidity pattern and outcome of patients admitted into a pediatric intensive care unit in India. Indian Journal of Clinical Medicine 2014;5:IJCM.S13902.

5 Tazebew AA, Cahkilu B, Bacha T. Admission pattern and outcome in a pediatric intensive care unit of Gondar university hospital. Ethiopian Medical Journal 2019;57.

6 Embu HY, Yiltok SJ, Isamade ES, et al. Paediatric admissions and outcome in a general intensive care unit. Afr J Paediatr Surg 2011;8:57.

7 Punchak M, Hall K, Seni A, et al. Epidemiology of disease and mortality from a PICU in Mozambique. Pediatr Crit Care Med 2018;19:e603-10.

8 Rady $\mathrm{H}$. Profile of patients admitted to pediatric intensive care unit, Cairo university hospital: 1-year study. Ain-Shams Journal of Anaesthesiology 2014;7:500.

9 Abebe T, Girmay M, G/Michael G, et al. The epidemiological profile of pediatric patients admitted to the general intensive care unit in an Ethiopian university hospital. Int J Gen Med 2015;8:63.

10 Haque A, Bano S. Clinical profile and outcome in a paediatric intensive care unit in Pakistan. J Coll Physicians Surg Pak 2009;19:534.

11 Rashma Ret al. Mortality profile of children admitted to intensive care unit of a tertiary care hospital in Kerala, South India. Int J Med Clin Sci 2018;1:13-16.

12 Galloway M, Hegarty A, McGill S, et al. The effect of ICU outof-hours admission on mortality: a systematic review and metaanalysis. Crit Care Med 2018;46:290-9.

13 Peeters B, Jansen NJG, Bollen CW, et al. Off-Hours admission and mortality in two pediatric intensive care units without 24-h in-house senior staff attendance. Intensive Care Med 2010;36:1923-7.

14 Zajic P, Bauer P, Rhodes A, et al. Weekends affect mortality risk and chance of discharge in critically ill patients: a retrospective study in the Austrian Registry for intensive care. Crit Care 2017;21:223.
15 Arabi Y, Alshimemeri A, Taher S. Weekend and weeknight admissions have the same outcome of weekday admissions to an intensive care unit with onsite intensivist coverage. Crit Care Med 2006;34:605-11.

16 Hixson ED, Davis S, Morris S, et al. Do weekends or evenings matter in a pediatric intensive care unit? Pediatr Crit Care Med 2005;6:523-30.

17 Aljabari S, Balch A, Larsen GY, et al. Severe sepsis-associated morbidity and mortality among critically ill children with cancer. $J$ Pediatr Intensive Care 2019;8:122-9.

18 Costa PdeO, Atta EH, Silva ARAda. Predictors of 7- and 30-day mortality in pediatric intensive care unit patients with cancer and hematologic malignancy infected with gram-negative bacteria. Braz J Infect Dis 2014;18:591-9.

19 Qureshi AU, Ali AS, Ahmad TM. Comparison of three prognostic scores (prism, PELOD and PIM 2) at pediatric intensive care unit under Pakistani circumstances. J Ayub Med Coll Abbottabad 2007;19:49-53.

20 Dhungana SP, Panta PP, Shrestha SK, et al. Performance of pediatric index of mortality-2 in a pediatric intensive care unit of a tertiary care hospital of Nepal. Nepal Medical College Journal 2019;21:89-94.

21 Arias Lopez MP, Fernández AL, Ratto ME, et al. Pediatric index of mortality 2 as a predictor of death risk in children admitted to pediatric intensive care units in Latin America: a prospective, multicenter study. J Crit Care 2015;30:1324-30.

22 Shukla VV, Nimbalkar SM, Phatak AG, et al. Critical analysis of PIM2 score applicability in a tertiary care PICU in Western India. Int $J$ Pediatr 2014;2014:1-7.

23 Solomon LJ, Morrow BM, Argent AC. Paediatric Index of Mortality scores: An evaluation of function in the paediatric intensive care unit of the Red Cross War Memorial Children's Hospital. Southern African Journal of Critical Care 2014;30:8-13.

24 Yousef RM, El Gendy F, Abd El Aziz A. Prognostic scoring systems in pediatric ICUs: pediatric risk of mortality III versus pediatric index of mortality 2. Alexandria Journal of Pediatrics 2019;32:27.

25 Dettmer MR, Damuth E, Zarbiv S, et al. Prognostic factors for long-term mortality in critically ill patients treated with prolonged mechanical ventilation: a systematic review. Crit Care Med 2017;45:69-74.

26 Sari DSP, Saputra I, Triratna S, et al. The pediatric index of mortality 3 score to predict mortality in a pediatric intensive care unit in Palembang, South Sumatera, Indonesia. Paediatr Indones 2017;57:164-70. 